\title{
A CONFIGURAÇÃO DISCURSIVA DO FEMININO NA POESIA DE CORA CORALINA: \\ ANÁLISE SEMIÓTICA DOS POEMAS “AQUELA GENTE ANTIGA" E "MEIAS IMPRESSÕES DE ANINHA (MÃE)”
}

\section{THE DISCURSIVE CONFIGURATION OF THE WOMAN IN THE POETRY OF CORA CORALINA: \\ SEMIOTIC ANALYSIS OF THE POEMS “AQUELA GENTE ANTIGA” AND "MEIAS IMPRESSÕES DE ANINHA (MÃE)”}

\author{
Mara Rúbia de Souza Rodrigues Morais ${ }^{1}$ \\ UFG - Universidade Federal de Goiás \\ Instituto Federal de Educação, Ciência e Tecnologia de Goiás
}

\begin{abstract}
RESUMO: A partir dos pressupostos da semiótica greimasiana, este estudo se propõe compreender a atualização da configuração discursiva do feminino em dois poemas de Cora Coralina, a saber: "Aquela gente antiga" e "Meias impressões de Aninha (mãe)". Para tanto, apoia-se numa teoria da construção dos sentidos que encontra sustentação na própria materialidade linguístico-discursiva e que, simultaneamente, focaliza os mecanismos "externos" de produção e recepção dos textos. Como resultado da análise, depreende-se que, embora sejam recobertos por um mesmo nome de autor, os textos analisados, neste estudo, apresentam variantes narrativas, temáticas e figurativas que participam da construção de sentidos distintos sobre a identidade da mulher. Enquanto no poema "Aquela gente antiga" é possível recuperar um percurso de geração do sentido que convalida a alteridade nos processos identitários do feminino, o segundo texto, "Meias impressões de Aninha (mãe)", é constituído por um percurso que engendra efeitos de desqualificação da alteridade. Em suma, este trabalho reafirma a possibilidade de constituição de discursividades distintas no interior de uma obra ou efeito-autor.
\end{abstract}

PALAVRAS-CHAVE: Configuração discursiva; identidade; alteridade; semiótica; percurso gerativo; Cora Coralina.

ABSTRACT: From the assumptions of the semiotic, this study aims to understand the discursive configuration of update of the feminine in two poems by Cora Coralina: "Aquela Gente Antiga" e "Meias Impressões de Aninha (mãe)". To this end, rests on a theory of construction of the senses that finds support in the very materiality and discursive language that simultaneously focuses on the mechanisms "outside" of production and reception of texts. As a result of the analysis, it appears that, although they are covered by the same author's name, the texts analyzed in this study show variants

\footnotetext{
${ }^{1}$ Professora do curso de Letras da Universidade Federal de Goiás - Campus de Jataí.

Disponível em: http://seer.fclar.unesp.br/casa
} 
narratives, thematics and figuratives participating in the construction of different meanings about the identity of the woman. While the poem "Aquela Gente Antiga" allows retrieve a route to generate the sense that validates the otherness of the feminine identity, the second text, "Meias impressões de Aninha (mãe)", consists of a route that generates effects of disqualification of otherness. In short, this study reaffirms the possibility of formation of differing discourses within a work-author or effect.

KEYWORDS: Discursive configuration; identity; otherness; semiotics; generative route; Cora Coralina.

\section{Considerações iniciais}

No conjunto das investigações que, direta ou indiretamente, focalizam os fatos de linguagem, não são raras as tentativas de se compreender as maneiras como uma dada cultura concebe um determinado tema ou assunto. Nesse contexto epistemológico, em que se entrevê o caráter heterogêneo do fenômeno linguístico e as diferenças de objetivo estabelecidas entre os domínios teóricos que dele se ocupam, as abordagens de cunho estruturalista dividem, com as análises contextuais do texto, o espaço da pesquisa sobre a irrupção dos conteúdos nas produções discursivas. Mediadas por propósitos distintos e, portanto, não sobrepostos, as diferentes perspectivas analíticas que se ocupam de unidades com extensão superior aos limites da frase inscrevem-se, respectivamente, numa concepção do texto como objeto de significação ou de comunicação, à medida que prestigiam a análise interna ou externa da sua constituição.

A partir da semiótica greimasiana, que postula a conciliação das dimensões interna e externa ${ }^{2}$ na análise do texto e concebe o sentido como produto de um percurso gerativo, este estudo se propõe compreender a atualização da configuração discursiva ${ }^{3}$ do feminino em dois poemas de Cora Coralina ${ }^{4}$, a saber: "Aquela gente antiga" e "Meias impressões de Aninha (mãe)" . Sendo assim, apoia-se numa teoria da construção dos sentidos que encontra sustentação na própria materialidade linguístico-discursiva e que, simultaneamente, focaliza os mecanismos ("externos") de produção e recepção dos textos, conforme acentua Barros (1997, p. 8):

Para explicar "o que o texto diz" e "como o diz", a semiótica trata, assim, de examinar os procedimentos da organização textual e, ao mesmo tempo, os mecanismos enunciativos de produção e de recepção do texto.

\footnotetext{
${ }^{2}$ Com relação à natureza da abordagem contextual realizada pela semiótica, é importante assinalar que, nesta teoria, a ordem do contexto remete, necessariamente, à esfera da intertextualidade constitutiva dos textos.

${ }^{3} \mathrm{Na}$ esteira das formulações da semiótica greimasiana, tomamos por configuração discursiva os "temas" amplos que figuram em diversos discursos. Segundo Fiorin (2000, p. 76), "uma configuração discursiva é um lexema do discurso que engloba várias transformações narrativas, diversos percursos temáticos e diferentes percursos figurativos".

${ }^{4}$ Cora Coralina é o pseudônimo de Ana Lins dos Guimarães Peixoto Bretas, poetisa goiana, nascida em Vila Boa ou Goiás Velho (antiga capital do estado de Goiás), que viveu entre 1889/1985 e que, entre 1956 e o ano da sua morte, escreveu livros de conto e poesia voltados para a rememoração do passado de Goiás.

${ }^{5}$ Textos que compõem a coletânea poética da obra Vintém de cobre: meias confissões de Aninha.
}

Disponível em: http://seer.fclar.unesp.br/casa 
Em termos gerais, desenvolve-se, aqui, o que Bertrand (2003) define como a articulação entre uma semiótica do enunciado e uma semiótica da enunciação, ao postular a integração da análise das relações internas do texto com as operações de discursivização.

Nesse movimento de busca pela explicitação dos sentidos dos textos, apresenta-se, a seguir, a análise dos mecanismos que convergem para a atualização de uma configuração discursiva em diferentes discursos. Mais especificamente, realiza-se uma incursão pelos diferentes níveis de construção dos sentidos dos textos (fundamental, narrativo e discursivo). Embora possam ser analisados separadamente, esses níveis não configuram compartimentos estanques da produção e interpretação textuais, tal como adverte a observação de Greimas e Courtés (1985, p. 206), em que o percurso gerativo do sentido é definido como:

[...] a economia geral de uma teoria semiótica [...], a disposição de seus componentes uns com relação aos outros, e isto na perspectiva da geração, isto é, postulando que, podendo todo objeto semiótico ser definido segundo o modo de sua produção, os componentes que intervêm nesse processo se articulam uns com os outros de acordo com um 'percurso' que vai do mais simples ao mais complexo, do mais abstrato ao mais concreto.

No encalço das diferentes variantes narrativas, temáticas e figurativas com as quais os diferentes narradores atualizam a configuração discursiva da mulher em diferentes materialidades literárias, segue, pois, a explicitação de uma gramática geral, que subjaz à estruturação e leitura dos textos. Uma explicitação que, pautada no plano de leitura do texto, disponibilizado por uma isotopia, ${ }^{6}$ reitera a constatação de que o texto admite uma, mas não qualquer leitura. Afinal: a leitura a ser realizada "não provém da fantasia do leitor, mas está inscrita no texto" (FIORIN, 2000, p. 81).

\section{“Aquela gente antiga" e a afirmação da alteridade: uma menina feia que}

\section{declamava Almeida Garret...}

Em Semântica estrutural, obra de importância capital para o estabelecimento da Semiótica, Greimas afirma que "a língua não é um sistema de signos, mas uma reunião [...] de estruturas de significação" (1976, p.30). Sob o crivo dessa formulação, é possível pensar a geração do sentido do texto "Aquela gente antiga", extraído do livro Vintém de cobre: meias confissões de Aninha, de Cora Coralina (p. 43-44):

\section{Aquela gente antiga}

Aquela gente antiga explorava a minha bobice.

Diziam assim, virando a cara como se eu estivesse distante:

"Senhora Jacinta tem quatro fulores mal falando.

Três acham logo casamento, uma, não sei não, moça feia num casa fácil."

Eu me abria em lágrimas. Choro manso e soluçado...

\footnotetext{
${ }^{6}$ Segundo Fiorin (2000, p. 81), isotopia "é a recorrência do mesmo traço semântico ao longo de um texto. Para o leitor, a isotopia oferece um plano de leitura, determina um modo de ler o texto".
}

Disponível em: http://seer.fclar.unesp.br/casa 
"Essa boba... Chorona... Ninguém nem falou o nome dela..." Minha bisavó ralhava, me consolava com palavras de ilusão: Sim, que eu casava. Que certo mesmo era menina feia, moça bonita. E me dava a metade de uma bolacha.

Eu me consolava e me apegava à minha bisavó.

Cresci com os meus medos e com o chá de raiz de fedegoso, prescrito pelo saber de minha bisavó.

Certo que perdi a aparência bisonha. Fiquei corada e achei quem me quisesse.

Sim, que esse não estava contaminado dos princípios goianos, de que moça que lia romance e declamava Almeida Garret não dava boa dona de casa.

Focalizando, num primeiro estágio da análise, o plano das relações fundamentais dessa materialidade textual, esse trabalho de remissão às categorias semânticas de base do texto identifica, num nível mais profundo e abstrato, a seguinte oposição, que se representa no quadrado:

$S_{1}$ identidade

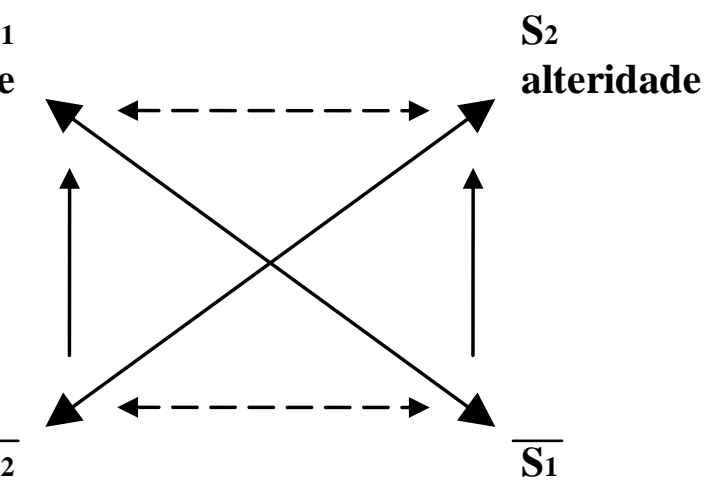

não alteridade não identidade

A partir das relações de contradição, de contraditoriedade e de complementaridade que se concretizam, nesse patamar do percurso gerativo do sentido, entre os termos da categoria tímica disforia vs. euforia, constitui-se a significação mínima do texto. Nesse estágio inicial da construção do sentido, engendra-se o núcleo semântico do texto que, pela via das diferentes relações entre os polos $S_{1}$ e $S_{2}$ (contrários); $S_{1}$ e $-S_{1}$ (contraditórios) / $\mathrm{S}_{2}$ e $\quad-\mathrm{S}_{2}$ (contraditórios); $-\mathrm{S}_{1}$ e $\mathrm{S}_{2}$ (complementares) / $\quad-\mathrm{S}_{2}$ e $\mathrm{S}_{1}$ (complementares), passa da negação de um termo disfórico (identidade) à afirmação de um eufórico (alteridade). Nesse nível fundamental das relações categoriais, o termo eufórico ${ }^{7}$ (instituído como um valor positivo) sustenta determinados valores acerca do feminino, que se pautam na afirmação da alteridade (figurativizada, num nível discursivo, como "moça que lia romance e declamava Almeida Garret") e na negação de uma identidade cristalizada pela tradição.

\footnotetext{
${ }^{7}$ A respeito do estabelecimento dos termos como eufóricos ou disfóricos, vale lembrar a observação de Fiorin (2000, p. 20) de que "euforia e disforia não são valores determinados pelo sistema axiológico do leitor, mas estão inscritos no texto. Assim, dois textos podem utilizar-se da categoria de base /natureza/ versus /civilização/ e valorizar, de maneira distinta, esses termos".
} 
Uma vez que cada um dos níveis do percurso de produção dos sentidos do texto é constituído, necessariamente, por um componente semântico e por um componente sintático, é preciso considerar, no batimento com a semântica do nível fundamental, a sintaxe que caracteriza esta etapa da formação do sentido. Nessa perspectiva, identifica-se a ocorrência das seguintes operações, que instalam o efeito de uma postulação da alteridade, em detrimento da identidade feminina tradicionalmente legitimada:

\section{(alteridade) \\ afirmação de $a$ (identidade), negação de $a$ (identidade), afirmação de $b$}

Integrando-se à semântica do nível fundamental, essa organização sintática elementar participa da instauração, no texto, do efeito de uma rememoração das práticas identitárias do feminino que são, simultaneamente, sobrepujadas por uma ordem de alteridade. Nessa instância da geração do sentido, arregimenta-se, com efeito, a proscrição de uma dada identidade da mulher. A essa identidade - que subordina a competência para o casamento aos valores sociais da beleza e da incompatibilidade entre desenvolvimento intelectual e aptidão para lidas domésticas - sobrepõe-se o reconhecimento de uma outra constituição feminina. Uma construção identitária capaz de redimensionar e relativizar a valorização da beleza como condição para o casamento e de conciliar a competência nas tarefas familiares com o engajamento cultural da mulher.

Considerando-se que a teoria semiótica se propõe explicitar os procedimentos de arregimentação do sentido que se deixam entrever na materialidade do próprio texto, é preciso ainda sustentar essa leitura na análise dos níveis narrativo e discursivo, que se interrelacionam com o nível profundo do texto em questão.

Na dinâmica de interpretação, que busca recuperar o sentido do texto no plano da narratividade, analisa-se a trajetória/percurso de um sujeito que, do ponto de vista da semiótica, é constituído tanto pela falta quanto pela busca de um objeto. Nesse sentido, abstrai-se, inicialmente, da organização narrativa do texto, um programa narrativo de base, no qual está pressuposto outro programa narrativo (de uso) que a ele se subordina. Abstrai-se, portanto, do nível narrativo, um programa principal (assumir uma identidade feminina socialmente legitimada) que, para se cumprir, requer um determinado programa de uso (adquirir beleza para conseguir casar-se).

Uma vez que a organização narrativa do texto se constitui, necessariamente, pelos estágios de manipulação, competência, performance e sanção, é preciso analisar cada uma dessas etapas inerentes à narratividade do texto, para se compreender a geração do seu sentido.

Focalizando, pois, o programa narrativo de base do texto, restitui-se, inicialmente, dos domínios desse programa, uma primeira manipulação, metodologicamente denominada aqui como manipulação A. Essa primeira manipulação (constituída no programa narrativo de base do texto) traduz-se, na sintaxe narrativa, pela incidência de um destinadormanipulador (a sociedade, representada por aquela gente antiga) sobre o destinatário (a menina), a fim de impingir, a esse destinatário, uma identidade feminina cristalizada pela tradição. A partir desta manipulação operada por provocação, a identidade da mulher, que é atrelada a um ideal de beleza e à "vocação" para lidas domésticas, passa a se constituir como o objeto de valor que o sujeito deve alcançar.

No encalço da manipulação A, institui-se uma competência (denominada, também para fins de análise, como competência A), visto que, para entrar em conjunção com o objeto valor, o sujeito precisa querer/poder; ou seja, precisa ter uma determinada 
competência. Essa competência relaciona-se, no texto, à obtenção, pelo destinatário, de uma aparência socialmente reconhecida, o que, para se realizar, supõe, no entanto, uma segunda manipulação, instituída como manipulação B.

$\mathrm{Na}$ instância dessa nova manipulação que é abstraída pela análise, inscreve-se a ação de um segundo destinador (a bisavó), que, pela via do consolo e do apoio efetivo (figurativizados pela "metade de uma bolacha" e pelo "chá de raiz de fedegoso"), manipula o sujeito para que ele possa entrar em conjunção com o objeto valor. Por meio desta manipulação, um segundo destinador torna o sujeito competente para realizar a performance socialmente esperada, ou seja, qualifica-o para tornar-se "atraente" e conseguir um marido.

A partir da manipulação $\mathbf{B}$, hierarquizada à competência $\mathbf{A}$, eis que se institui, no programa narrativo de uso, a competência do sujeito (competência B), que é encaixada no programa narrativo de base e representada, nesse discurso literário, pelos enunciados de fazer e de estado: "Cresci com os meus medos" / "perdi a aparência bisonha" / "Fiquei corada e achei quem me quisesse".

Integrada a essa competência, realiza-se, no espaço do programa de uso que é suposto pelo programa de base do texto, uma primeira performance do sujeito (performance $B$, também encaixada numa competência $\mathbf{A})$. Essa performance, que é regida pelas modalidades do dever, do querer e do poder fazer, é revestida, no plano do discurso (como se verá a seguir), pela figurativização do tema do casamento em: "achei quem me quisesse". Realiza-se, pois, uma performance que será sancionada positivamente no plano deste programa de uso (sanção B), uma vez que o destinador-julgador (o marido) reconhece a competência do sujeito para o fazer (casar-se). Em síntese: o destinador-julgador convalida os movimentos identificatórios do sujeito (a moça), cuja identidade se movimenta entre as representações tradicionalmente atribuídas à mulher e outras identificações operadas, por exemplo, numa esfera de intelectualidade: "moça que lia romance e declamava Almeida Garret".

Feita a análise do programa de uso, que se encaixa na fase de competência $\mathbf{A}$ (do programa principal do texto), prossegue-se com a descrição das etapas da performance (A) e da sanção $(\boldsymbol{A})$ do programa de base do texto. Suspensas temporariamente pela observação do programa de uso que se arregimenta no interior da competência A, essas etapas são fundamentais à produção e à análise de sentidos sobre o feminino no texto.

Da fase da performance $A$, restitui-se a ação do sujeito, que "lê romance e declama Almeida Garret" e que ainda é "boa dona de casa". Realizada essa performance, o sujeito é sancionado positivamente (sanção A), uma vez que é reconhecido como capaz de inscrever-se numa identidade feminina que concilia algumas representações tradicionais da mulher com uma dada alteridade.

A partir da análise da organização narrativa do texto, depreende-se a seguinte formalização, que permite visualizar a hierarquização dos programas constitutivos do sentido:

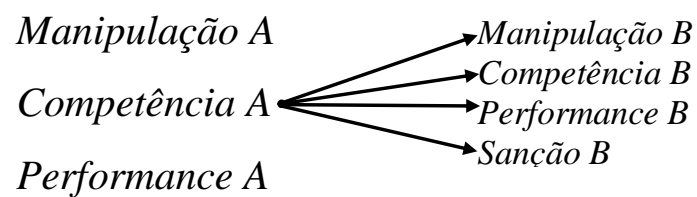

Sanção A 
Na instância da sintaxe do nível narrativo, assinala-se, ainda, a irrupção de diferentes enunciados-elementares (instituídos como enunciados de estado e de fazer). Nessa dimensão do percurso gerativo, reconhece-se que o sujeito "menina feia" entra em conjunção com alguns objetos, como se lê nos enunciados: "Certo que perdi a aparência bisonha". "Fiquei corada" "e achei quem me quisesse". Aqui, a relação de conjunção do sujeito com os valores investidos nos objetos (beleza; casamento), traduz-se na formulação a seguir, que permite visualizar o programa narrativo, que se apresenta como "a unidade operatória elementar da organização narrativa de um texto" (BARROS, 1997, p. 20):

$$
\mathrm{PN}=\mathrm{F}\left[\mathrm{S}_{1} \rightarrow\left(\mathrm{S}_{2} \cap \mathrm{O}_{\mathrm{v}}\right)\right]
$$

Por meio desta formulação, visualiza-se que, nos diferentes programas narrativos do texto, um sujeito do fazer $\left(S_{1}\right)$ opera uma função de transformação $(\rightarrow)$ no sujeito do estado $\left(\mathrm{S}_{2}\right)$. No caso do programa narrativo de base do texto, esse sujeito do estado entra em relação de conjunção com um dado objeto valor (o casamento), o que constitui esse programa narrativo como um PN transitivo e de apropriação ${ }^{8}$.

Conforme esta análise já insinuou, o desdobramento da formulação PN = $\mathrm{F}\left[\mathrm{S}_{1} \rightarrow\left(\mathrm{S}_{2} \cap \mathrm{O}_{\mathrm{v}}\right)\right]$ concretiza, em "Aquela gente antiga", a ocorrência de um programa narrativo de uso, que, ao encaixar-se no programa principal, compõe os percursos do sujeito, do destinador-manipulador e do destinador-julgador nesse texto. Sobretudo porque, assim como o programa principal, ele engloba tanto as etapas de manipulação e sanção, como as instâncias da competência (fase em que, segundo Fiorin, o sujeito é dotado de um saber e/ou poder fazer para realizar a transformação) e da performance (fase em que se processa a transformação central da narrativa).

Como se vê, no encalço do percurso narrativo do sujeito, que se constitui pelo encadeamento de diferentes programas narrativos, participam, ainda, da gramática narrativa do texto, os percursos do destinador-manipulador e do destinador-julgador, tangenciados nos parágrafos anteriores. No sentido desta constatação, leem-se as trajetórias dos actantes funcionais cujos papéis primordiais, na narrativa, se constituem, respectivamente, como o de doador, ao sujeito, dos valores modais indispensáveis à realização da performance, e de sancionador da ação/transformação empreendida no/pelo sujeito.

Quanto a esse primeiro papel actancial, é possível visualizá-lo, no poema de Cora Coralina, pela modalidade do dever fazer (relacionada à competência para a realização da performance de casar-se). Esse objeto modal, que é disponibilizado ao sujeito por meio da manipulação realizada, inicialmente, por um destinador ("aquela gente antiga"), processa-se pela via da provocação, que, juntamente com outros diferentes tipos de manipulação (por tentação, intimidação e sedução), são passíveis de se constituir na esfera narrativa dos textos. $\mathrm{Na}$ esteira desse objeto-modal, situado na esfera do dever-fazer, constitui-se uma outra posição de objeto ${ }^{9}$ (casamento) como valor com que se busca a conjunção na performance esperada e realizada. Esse desdobramento dos objetos articula-se, na sequência narrativa, à relação estabelecida entre dois programas distintos (um programa de base e um programa de uso), uma vez que a transformação operada pelo sujeito (entrar em conjunção com o objeto

\footnotetext{
${ }^{8}$ De acordo com Barros (1997, p. 21-22), há diferentes tipos de programas narrativos, que se estabelecem segundo critérios diversos, tais como: a) natureza da função; b) complexidade e hierarquia de programas; c) valor investido no objeto; d) relação entre os actantes narrativos e os atores que os manifestam no discurso.

9 A respeito da configuração dos objetos (objetos modais e objetos-valor) como posições na sequência narrativa, conferir Fiorin (2000, p. 29).
} 
casamento) prescinde da conjunção prévia com outro objeto ("fiquei corada", "perdi a aparência bisonha").

Com relação ao papel actancial do destinador-julgador, que opera a sanção por meio do reconhecimento da ação e da transformação do sujeito, assinala-se, na sanção B, abstraída do texto, a função do actante "marido", que sanciona cognitiva e positivamente a realização da performance ("fiquei corada", "perdi a aparência bisonha") pelo sujeito. Ou seja, o reconhecimento da alteridade constitutiva do sujeito (que de "menina feia", passou a moça "corada" e, mesmo declamando Almeida Garret, se fez "boa dona de casa") constitui o percurso do destinador-julgador, que convalida a realização da performance possibilitada pela competência atribuída ao sujeito por meio da manipulacão.

Além desse percurso do destinador-julgador "marido", configura-se, ainda, no texto, o papel actancial da "sociedade", como um outro destinador-julgador. Inserida no programa de base do texto e remontando a uma performance principal, a sanção realizada por esse destinador associa-se ao reconhecimento da ação/transformação do sujeito de estado. Esse sujeito de estado, por sua vez, entra em conjunção com o objeto-valor (casamento) por meio da competência (traduzida na modalidade do poder-fazer) para a performance: casarse/ser boa dona de casa. Com esse movimento, configura-se, pois, a construção de um efeito de sentido que, simultaneamente, reitera determinados papéis actanciais para o sujeito mulher (identificado com as funções domésticas) e afirma outros elementos da sua constituição identitária. Valoriza-se, como termo eufórico, o polo da alteridade, em que se localizam determinados aspectos da identidade feminina ("moça que lia romance e declamava Almeida Garret"), que escapam à ordem de identidade asseverada pela conjuntura social do passado.

Num patamar mais superficial do percurso gerador do sentido, encontram-se as estruturas discursivas, que resultam da assunção, pelo sujeito, das estruturas semionarrativas. Nas suas dimensões sintática e semântica, a esfera do discurso remonta, respectivamente, às relações do sujeito da enunciação com o discurso-enunciado e aos procedimentos temáticos e figurativos, que são definidos em Fiorin (2000, p. 64):

Tematização e figurativização são dois níveis de concretização do sentido. [...] Assim, a figura é todo conteúdo de qualquer língua natural ou e qualquer sistema de representação que tem um correspondente perceptível no mundo natural. [...] Tema é um investimento semântico, de natureza puramente conceptual, que não remete ao mundo natural. Temas são categorias que organizam, categorizam, ordenam os elementos do mundo natural.

Focalizando-se a discursivização dos valores analisados no nível narrativo do texto, constata-se, no plano da sua semântica discursiva, o revestimento dos temas por determinadas figuras, que recebem investimento eufórico ou disfórico. São representativos desta ocorrência os procedimentos figurativos em que o tema da proscrição da alteridade no contexto do passado é ancorado nas figuras desqualificadoras "aquela gente antiga" e "diziam virando a cara", às quais o discurso atribui um valor negativo. Já em "me dava a metade de uma bolacha" e "cresci com o chá de raiz de fedegoso prescrito pelo saber de minha bisavó", a figurativização empreendida é apreciada positivamente e recobre os percursos temáticos abstratos, que, por sua vez, concretizam os percursos narrativos do sujeito e do destinador. Em perspectiva análoga, o mecanismo figurativo eufórico, em "moça que lia romance e declamava Almeida Garret" e "boa dona de casa", participa da construção de um sentido de convalidação e ressignificação da alteridade. Esse sentido se constitui na relação (de 
contradição e contraditoriedade) com uma identidade feminina assentada em padrões conservacionistas e avessos à reformulação. Participa, pois, de uma produção de sentidos que baliza a configuração discursiva do feminino no poema em questão e que se dá na interdependência dos diferentes estágios do percurso gerativo da significação do texto.

Nos domínios de uma sintaxe do nível discursivo, encontram-se, ainda, alguns elementos que entretecem uma configuração discursiva da mulher no poema analisado. Entre esses elementos, destacam-se as diferentes projeções da enunciação sob as quais o discurso se estrutura, uma vez que:

a enunciação projeta, para fora de si, os actantes e as coordenadas espaciotemporais do discurso, que não se confundem com o sujeito, o espaço e o tempo da enunciação. [...] Em outras palavras, o sujeito da enunciação faz uma série de opções para projetar o discurso, tendo em vista os efeitos de sentido que deseja produzir. (FIORIN, 2000, p. 54).

Apesar da ambiguidade da relação que a semiótica greimasiana estabeleceu com a problemática enunciativa - tendo passado da exclusão radical da enunciação à apropriação dessa categoria, sob a égide do uso -, é possível incluir o programa semiótico entre as teorias que se dedicam ao estudo da subjetividade no discurso. Voltada para a análise do discurso em ato, essa abordagem, no entanto, coloca-se à distância da análise do sujeito real e concebe o sujeito discursivo como uma "instância em construção, sempre parcial, incompleta e transformável, que apreendemos a partir dos fragmentos do discurso realizado" (BERTRAND, 2003, p. 83). Nesse sentido, Greimas (1975, p. 27) manifesta sua desconfiança em relação a um sujeito soberano/fonte do dizer e reitera o princípio que designa como a "imanência tão laboriosamente construída do objeto-linguagem" no interior da semiótica:

Não se percebe de que maneira, sem voltar a cair numa ontologia do sujeito, de que a semiótica literária a tão duras penas se libertou, seria possível conceber a definição do sujeito da enunciação a não ser através da totalidade de suas determinações textuais.

Inscrevendo-se, portanto, numa dinâmica de busca pelas figuras da enunciação, manifestadas e operacionalizadas no próprio texto, a semiótica propicia uma análise da materialidade discursiva, capaz de alcançar a ordem das restrições que determinam a produção do discurso, a saber:

[...] as imposições a priori das categorias morfossintáticas e os limites, de ordem sociocultural, impostos pelo hábito, pelas ritualizações, pelos esquemas, pelos gêneros, e até pela fraseologia, que moldam e modelam, sem que o saibamos, a previsibilidade e as expectativas de sentido. (BERTRAND, 2003, p. 87).

Entrelaçada à concepção de enunciação assumida pela semiótica, que se situa na perspectiva do uso e da discursivização, a elaboração das noções, entre si 
complementares, de debreagem/embreagem ${ }^{10}$ deriva para a postulação do primado do ele sobre o eu. Esta formulação, que assevera a impossibilidade de uma embreagem actancial integral (pois nenhum eu localizado no discurso pode ser tomado como o sujeito da enunciação propriamente dita), se insinua bastante produtiva para a análise da materialidade em questão nesta proposta de investigação. Uma vez que o corpus deste estudo é composto por uma textualidade de caráter autobiográfico, parece pertinente pensar, à luz da teoria semiótica, a construção de efeitos de proximidade e realidade, operada pelo jogo enunciativo, num movimento em que, segundo Bertrand (2003, p. 93-94):

[...] mesmo na autobiografia, discurso embreado por excelência, o "eu" que enuncia como ancoragem exclusiva do discurso não constitui uma embreagem actancial integral, designando a pessoa efetiva: ele é sempre um simulacro construído do escritor, que se define no interior do texto por suas relações com os outros atores aí instalados (pela genealogia, por exemplo), assim como com as categorias espaciais (seu lugar de nascimento) e temporais (sua época), que são também debreadas.

De acordo com a definição de Floch (2001, p.16), "a enunciação [...] é uma instância logicamente pressuposta por todo enunciado, e o enunciador é o sujeito produtor deste enunciado". Na mesma direção, lê-se, em Fiorin (2000, p. 40), que o sujeito produtor do discurso desdobra-se num enunciador e num enunciatário, sendo que o primeiro realiza um fazer persuasivo, enquanto o enunciatário realiza um fazer interpretativo. No encalço dos efeitos produzidos pelas projeções da enunciação no discurso, analisam-se, no texto de Cora Coralina, os simulacros de proximidade e realidade, obtidos, sobretudo, por meio dos mecanismos de debreagem enunciva e enunciativa, formulados por Fiorin (2000, p. 41):

[...] uma debreagem é o mecanismo em que se projeta no enunciado quer a pessoa (eu/tu), o tempo (agora) e o espaço (aqui) da enunciação, quer a pessoa (ele), o tempo (então) e o espaço (lá) do enunciado. No primeiro caso (projeção do eu-aqui-agora), ocorre uma debreagem enunciativa; no segundo, (projeção do ele-então-lá), acontece uma debreagem enunciva.

Em "Aquela gente antiga", o efeito autobiográfico se produz pela alternância das projeções da enunciação. Visto que a debreagem enunciativa (projeção do eu/aqui/agora) coexiste com "porções" textuais estruturadas sob a debreagem enunciva (projeção do ele/então/lá), instala-se, no discurso, ao lado do narrador em primeira pessoa, um observador que se mantém a uma determinada distância dos demais actantes da narrativa. Como efeitos dessa complexa trama enunciativa, predominam, contudo, os simulacros de proximidade e subjetividade "na visão dos fatos vividos e narrados por quem os viveu, que os passa, assim, impregnados de 'parcialidade'" (BARROS, 1997, p. 57).

Com relação à organização temporal do texto, identifica-se uma predominância do sistema enuncivo ancorado no marco referencial pretérito, sendo que o tempo referencial do então (que remonta a uma debreagem espacial do lá) é não concomitante com o agora da enunciação. Nessa organização temporal dominante no texto, sustentam-se determinados efeitos de subjetividade semelhantes aos referidos na análise da projeção enunciativa

\footnotetext{
${ }^{10}$ Segundo Fiorin (2000, p. 52), “a embreagem é o mecanismo em que ocorre uma suspensão das oposições de pessoa, de tempo ou de espaço".
} 
actancial, haja vista que o discurso produz um simulacro da escrita autobiográfica, instituída no liame entre a história e a ficção.

Ainda no espaço da construção dos efeitos produzidos pelas projeções da enunciação, destaca-se o mecanismo da debreagem indireta, que, neste texto, constrói o efeito de realidade sobre os fatos e temas rememorados. Nesse sentido, assinalam-se as ocorrências em que "no interior do texto, cede-se a palavra aos interlocutores, em discurso indireto, constrói-se uma cena que serve de referente ao texto e cria-se a ilusão de situação 'real' de diálogo" (BARROS, 1997, p. 59):

a) "Senhora Jacinta tem quatro fulores mal falando.

Três acham logo casamento, uma, não sei não, moça feia num casa fácil” (CORALINA, 2001, p. 43)

b) Essa boba... Chorona... Ninguém nem falou o nome dela..." (CORALINA, 2001, p. 43)

Articulado a esse dispositivo da debreagem indireta (ou de segundo grau), participa da construção de um efeito de realidade uma outra modalidade de procedimento discursivo que, no entanto, se inscreve nos domínios de uma semântica discursiva. Trata-se do mecanismo da ancoragem, por meio do qual o discurso é colado a pessoas, datas e locais, que, segundo Barros (1997, p. 60), o receptor reconhece como "reais" ou "existentes". Como exemplos deste procedimento que produz a ilusão de realidade no discurso, consideram-se: a nomeação da personagem ("Senhora Jacinta"); a delimitação, pela via do adjetivo pátrio, do espaço tematizado ("esse não estava contaminado dos princípios goianos de que moça que lia romance e declamava Almeida Garret não dava boa dona de casa"); assim como o fornecimento de elementos da realidade cultural (a remissão a "Almeida Garret", por exemplo), projetados como informações partilhadas pelo enunciador e pelo enunciatário.

A partir desses elementos, que participam do que Barros (1997, p. 62) define como uma análise "completa" do texto (operada nos âmbitos fundamental, narrativo e discursivo), reconstroem-se, aqui, as relações entre os procedimentos discursivos e a produção dos efeitos de sentido sobre o feminino nesta materialidade literária. Nesse movimento, identifica-se, em meio às ilusões de proximidade e realidade, construídas pelo discurso, a produção de um simulacro do sujeito narrador das próprias memórias, que, ao narrar a sua experiência "subjetiva" e "real", subverte uma constituição identitária do feminino assentada sobre a proscrição da alteridade.

Isto posto, e prosseguindo com o trabalho de compreensão das formas de atualização da configuração discursiva do feminino no corpus de estudo, passa-se, a seguir, à análise semiótica do segundo poema de Cora Coralina: "Meias impressões de Aninha (mãe)".

\section{de Aninha (mãe)"}

A identidade feminina e a proscrição da alteridade nas "Meias impressões

Conforme já se assinalou, é possível que dois textos se utilizem de uma mesma categoria de base, mas valorizem, de maneira distinta, os termos que a constituem. Isso porque, de acordo com a rememorada observação de Fiorin (2000, p. 20), o valor (eufórico ou disfórico) desses termos está inscrito no próprio texto e não é determinado pelo sistema axiológico do leitor. 
Partindo desse pressuposto, este estudo se dedica à análise semiótica do poema "Meias impressões de Aninha (mãe)", também extraído da obra Vintém de cobre: meias confissões de Aninha, de Cora Coralina (p. 190-191):

\author{
Meias impressões de aninha (mãe) \\ Renovadora e reveladora do mundo \\ A humanidade se renova no teu ventre. \\ Cria teus filhos, \\ não os entregues à creche. \\ Creche é fria, impessoal. \\ Nunca será um lar \\ para teu filho. \\ Ele, pequenino, precisa de ti. \\ Não o desligues da tua força maternal. \\ Que pretendes, mulher? \\ Independência, igualdade de condições... \\ Empregos fora do lar? \\ És superior àqueles \\ que pretendes imitar. \\ Tens o dom divino \\ de ser mãe. \\ Em ti está presente a humanidade. \\ Mulher, não te deixes castrar. \\ Serás um animal somente de prazer \\ $\mathrm{e}$, às vezes, nem mais isso. \\ Frígida, bloqueada, teu orgulho te faz calar. \\ Tumultuada, fingindo ser o que não és. \\ Roendo o teu osso negro da amargura.
}

Uma vez que, assim como no texto anterior, os sentidos sobre a identidade feminina se constituem, num nível fundamental, a partir das relações entre os termos alteridade / identidade, procura-se, aqui, compreender: como e por que diferentes textos, que são agregados sob o mesmo "nome de autor", produzem diferentes sentidos acerca da mulher? Busca-se, em suma, abstrair a configuração discursiva do feminino nesses textos, tendo em vista que "se, no interior de um único texto, é possível depreender percursos figurativos, temáticos e narrativos, a depreensão da configuração discursiva só é possível a partir do confronto de vários discursos" (FIORIN, 200, p. 76). Nessa perspectiva, realiza-se a leitura que parte do nível profundo do texto, passa pela sua organização narrativa e alcança o plano da discursivização, em que os valores narrativos são revestidos por temas, que, por sua vez, se concretizam em determinadas figuras.

Com relação à operação mínima de sentido do texto, processada no nível fundamental, tem-se, em "Meias impressões de Aninha (mãe)", que as relações categoriais partem da oposição alteridade $\mathbf{x}$ identidade, sendo o segundo termo investido de valor eufórico (diferentemente do que ocorre no poema "Aquela gente antiga"). Essa rede de relações, que sustentam o encaminhamento ideológico do discurso e constituem, num outro plano, o ethos do enunciador - traduzido, por Discini (1997), como "o caráter de quem diz dado pelo modo de dizer" - , representa-se no seguinte quadrado semiótico: 


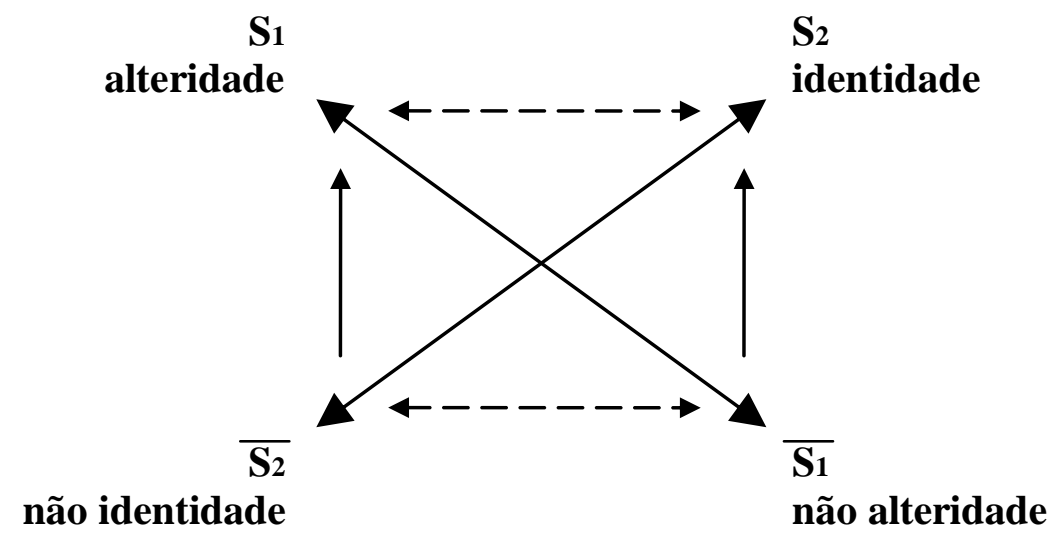

Com base na teoria semiótica, é possível compreender os rendimentos da oposição mínima constituída nesse nível do percurso gerativo do sentido, a partir da análise dos seus desdobramentos. Desse modo, verifica-se que a oposição entre os polos da alteridade $\left(\mathrm{S}_{1}\right)$ e da identidade $\left(\mathrm{S}_{2}\right)$ se assenta numa relação de contradição, assim como numa relação de contraditoriedade entre esses termos, aos quais se aplica uma operação de negação. E, uma vez que cada um dos extremos: não alteridade e não identidade acaba convergindo para o termo contrário daquele que o gerou, institui-se ainda, nesse nível das relações elementares do texto, ao lado das relações de contradição e de contraditoriedade, as relações de complementaridade, estabelecidas entre os polos dos eixos: $-S_{1} / S_{2}$ e $-S_{2} / S_{1}$. Dessas relações, advém a unidade mínima de sentido do texto, que assevera o recobrimento da alteridade (revestida, no plano discursivo, por figuras como "animal somente de prazer", "frígida, bloqueada") pela ordem da identidade tradicionalmente constituída para a mulher. Essa identidade feminina, que passa a ser o objeto valor a ser perseguido pelo sujeito, define-se, na semântica discursiva, por temas, como a sublimação da maternidade; a supremacia da maternidade sobre as demais instâncias da constituição identitária da mulher, entre outros, que se revestem nas figuras: "Mãe", "Renovadora e reveladora do mundo", "Em ti está presente a humanidade".

O nível narrativo de construção do sentido do texto instaura um encadeamento de programas narrativos, que supõem a ação de um sujeito de fazer sobre um sujeito de estado. Esse encadeamento de programas, nos quais o estado de conjunção ou disjunção do sujeito com o objeto (a identidade feminina) é transformado, constitui o esquema narrativo do texto. Nele, depreendem-se os percursos do sujeito, do destinador-manipulador e do destinador-julgador, que se instituem nas fases de manipulação (percurso do destinadormanipulador), de competência e performance (percurso do sujeito) e de sanção (do destinador-julgador).

Constituindo a esfera do percurso de um destinador-manipulador, instaura-se, no texto, a fase de manipulação, em que a representação do destinador-manipulador (o enunciador) manipula, pela via da sedução ("És superior àqueles que pretendes imitar"), um destinatário (a mulher), instituído, discursivamente, como o tu. Essa instalação do leitor (“Que pretendes, mulher?") como enunciatário (ou seja, como o tu), a quem é atribuída uma competência ("Tens o dom divino de ser mãe") constitui-se, perante as instâncias de produção e recepção do texto, como uma operação argumentativa. Sobretudo porque se espera que o sujeito manipulado realize uma dada performance, ao entrar em conjunção com um objeto de desejo (a identidade maternal), radicado em ideais de resignação e renúncia de si. $\mathrm{Na}$ esfera da narratividade, engendra-se, portanto, um programa narrativo de apropriação, 
que baliza o percurso do sujeito (a mulher, instituída como enunciatário), composto pelas fases de competência e performance.

No que toca à etapa de sanção, constitutiva do percurso do destinadorjulgador, verifica-se, nesse texto, que ela se apresenta de maneira implícita, e entrelaçada aos valores estabelecidos na fase de manipulação, visto que a mãe é sancionada/reconhecida como "renovadora e reveladora do mundo". Compondo uma cena discursiva de aconselhamento, que visa conduzir o sujeito a realizar uma performance e a entrar em conjunção com o objeto valor (a identidade de mãe), esse programa narrativo de sanção (inserido no percurso do destinador-julgador) dá lugar à representação em que:

[...] o destinador interpreta as ações do destinatário-sujeito, julga-o, segundo certos valores, e dá-lhe a retribuição devida, sob a forma de punições ou de recompensas. (BARROS, 1997, p. 89).

Tendo em vista que o nível narrativo abriga um entrelaçamento de programas que engendra os sentidos do texto, é preciso analisar um segundo programa narrativo (de uso), que se encaixa no programa narrativo de base acima descrito.

Desse programa, que incide sobre o programa narrativo principal, restituem-se as fases de manipulação, competência, performance e sanção, que compõem os percursos narrativos do texto. Nesse sentido, visualiza-se, numa fase de manipulação, a situação em que o sujeito do fazer (o destinador-manipulador, representado pela sociedade moderna), opera, sobre o sujeito de estado, uma manipulação por sedução (pressuposta nas promessas de independência e igualdade de condições).

Realizada a manipulação, a narratividade se arregimenta na esteira de um percurso do sujeito (ou da ação), constituído pelas etapas de competência e performance. Ao ser dotado de um dever fazer ou de um querer fazer (que se traduzem, respectivamente, pela necessidade ou pelo desejo de dedicar-se à sua dimensão profissional), o sujeito assume competência para uma dada performance (concretizada, por sua vez, na ação de assumir "empregos fora do lar").

No encalço do percurso do sujeito, que é dotado de competência e realiza a performance, constitui-se, no plano narrativo, um nova etapa de sanção, que engendra o percurso do destinador-julgador. Por meio do julgamento do sujeito da ação, realiza-se um sancionamento, que se apresenta, de maneira explícita, sob a forma de advertência dirigida ao enunciatário: "serás um animal somente de prazer / e às vezes nem mais isso".

Com vistas a uma melhor visualização das relações estabelecidas, no nível narrativo, entre os programas de base e de uso que constituem o seu sentido nesse patamar da significação, apresenta-se, a seguir, o esquema narrativo que se encontra pressuposto ao texto:

\begin{tabular}{|c|c|c|c|c|}
\hline $\begin{array}{c}\text { Programas } \\
\text { narrativos }\end{array}$ & $\begin{array}{l}\text { Percurso do } \\
\text { destinador- }\end{array}$ & \multicolumn{2}{|c|}{ Percurso do sujeito da ação } & $\begin{array}{l}\text { Percurso do } \\
\text { destinador- }\end{array}$ \\
\hline $\begin{array}{c}\text { Programa narrativo } \\
\text { de base }\end{array}$ & $\begin{array}{l}\quad \text { Manipulação } \\
\text { O destinador } \\
\text { manipulador dota o } \\
\text { destinatário } \\
\text { manipulado de um } \\
\text { dever fazer algo } \\
\text { (assumir a } \\
\text { identidade de mãe) }\end{array}$ & $\begin{array}{l}\text { Competência } \\
\text { O sujeito do fazer } \\
\text { adquire/possui um } \\
\text { saber e um poder } \\
\text { ("Tens o dom divino } \\
\text { de ser mãe") }\end{array}$ & \begin{tabular}{l}
\multicolumn{1}{c}{$\begin{array}{c}\text { Performance } \\
\text { (esperada) }\end{array}$} \\
O sujeito do fazer \\
executa a ação ("cria \\
os filhos")
\end{tabular} & \begin{tabular}{l}
\multicolumn{1}{c}{ Sanção } \\
O destinador passa a \\
julgar o sujeito da \\
ação, com base nos \\
valores estabelecidos \\
na fase de \\
manipulação (a mãe \\
é sancionada como \\
"renovadora e
\end{tabular} \\
\hline
\end{tabular}

Disponível em: http://seer.fclar.unesp.br/casa 


\begin{tabular}{|c|c|c|c|c|}
\hline & & & & $\begin{array}{l}\text { reveladora do } \\
\text { mundo") }\end{array}$ \\
\hline $\begin{array}{c}\text { Programa narrativo } \\
\text { de uso }\end{array}$ & $\begin{array}{l}\quad \text { Manipulação } \\
\text { O destinador } \\
\text { manipulador dota o } \\
\text { destinatário } \\
\text { manipulado de um } \\
\text { dever/querer fazer } \\
\text { algo (assumir } \\
\text { empregos fora do } \\
\text { lar; entregar os filhos } \\
\text { à creche; buscar } \\
\text { independência e } \\
\text { igualdade de } \\
\text { condições) }\end{array}$ & $\begin{array}{l}\text { Competência } \\
\text { O sujeito do fazer } \\
\text { adquire um saber e } \\
\text { um poder (o sujeito } \\
\text { consegue/pode } \\
\text { "fingir ser o que não } \\
\text { é") }\end{array}$ & $\begin{array}{l}\quad \text { Performance } \\
\text { O sujeito do fazer } \\
\text { executa a ação } \\
\text { (arruma empregos } \\
\text { fora do lar; entrega os } \\
\text { filhos à creche; luta } \\
\text { por independência e } \\
\text { igualdade de } \\
\text { condições) }\end{array}$ & $\begin{array}{l}\qquad \text { Sanção } \\
\text { O destinador passa a } \\
\text { julgar o sujeito da } \\
\text { ação, com base nos } \\
\text { valores estabelecidos } \\
\text { na fase de } \\
\text { manipulação (por } \\
\text { meio da } \\
\text { advertência/ameaça: } \\
\text { "Serás um animal } \\
\text { somente de prazer e } \\
\text { às vezes nem mais } \\
\text { isso") }\end{array}$ \\
\hline
\end{tabular}

Levando em consideração a interdependência dos fatos dos níveis fundamental, narrativo e discursivo, analisam-se, a seguir, algumas projeções da instância da enunciação, que se realizam no enunciado. A partir da constatação de que a manipulação operada no nível narrativo (que dota o sujeito de um querer fazer) sustenta as estratégias discursivas, passa-se, agora, à observação das projeções actanciais, temporais e espaciais, que configuram a sintaxe discursiva do poema.

De acordo com Fiorin, há três tipos de debreagens enuncivas e enunciativas, que são: as actanciais (de pessoa), as temporais (de tempo) e as espaciais (de espaço). Dado que as projeções da enunciação não se processam aleatoriamente e participam, portanto, da construção de determinados efeitos de sentido, assinala-se, no poema, o mecanismo de sustentação do texto numa temporalidade concomitante ao agora do ato de dizer. Desse procedimento, que articula o nível discursivo à manipulação e à construção da competência do leitor, empreendidas no nível narrativo, resulta o efeito argumentativo, que concede legitimidade ao enunciador das verdades "atemporais". Pela via da debreagem temporal, instaura-se, no discurso, o efeito de uma presentificação ominitemporal, ditada pelo batimento das formas imperativas ("não os entregues à creche"; "Não o desligues da tua força maternal"; "não te deixes castrar") com o presente do indicativo ("A humanidade se renova no teu ventre"; "Creche é fria, impessoal"; És superior àqueles que pretendes imitar"; "Tens o dom divino de ser mãe"; "Em ti está presente a humanidade"). Engendra-se, assim, na superfície do texto, uma arquitetura enunciativa, que compõe a cena de aconselhamento, assim como o efeito de verdade de uma construção identitária da mulher, assentada, primordialmente, na esfera da maternidade.

No âmbito da organização actancial do discurso, identifica-se a construção de um efeito de proximidade (subjetividade), articulado à instalação do simulacro em que um eu (enunciador) assume a responsabilidade pelos conselhos ministrados e instaura um tu como seu enunciatário. Uma vez que, conforme Barros (1997, p. 57), a enunciação é sempre pressuposta e nunca é manifestada no texto em que se projeta, a cena interativa entre enunciador e enunciatário não é mais do que efeito discursivo. Da mesma forma, a sensação de proximidade, estabelecida entre os atores do discurso (que exercem papéis actanciais na narrativa), deriva das projeções da enunciação, que visa, em última instância, produzir o efeito de verdade dos sentidos enunciados no texto. Em linhas gerais, verifica-se que, da organização actancial do discurso, provém o efeito de convalidação de uma identidade feminina, que se afirma no movimento simultâneo de negação da alteridade e dos valores 
assumidos pelos atores do enunciado: "És superior àqueles que pretendes imitar"; "Tumultuada, fingindo ser o que não és"; "Roendo o teu osso negro da amargura".

A partir do batimento entre a sintaxe e a semântica discursivas, constitui-se, no texto em questão, o percurso em que os investimentos actancial, espacial e temporal discursivizam a cena do aconselhamento, por meio de figuras que se ancoram em temas. Rememorando as formulações acerca dos percursos temáticos e figurativos, anteriormente apresentados, neste trabalho, pela referência a Fiorin (2000), pode-se ler, em Discini (2005, p. 270), que os temas:

[...] reconstroem o mundo, dado como representação conceitual e simbólica (...) apresentam-se como conceitos que recortam simbolicamente a realidade, reconstroem o mundo, sob a interpretação de um sujeito submetido ao ideário das formações sociais; lexicalizam-se por meio de um grau maior de abstração, se comparados às figuras; são investidos, pela enunciação, de valor eufórico ou disfórico, consolidando visões de mundo.

Tendo em vista que, de acordo com a semiótica, os percursos temáticos conjugam-se aos percursos figurativos para constituir o sentido do texto, vale lembrar, ainda, que:

[...] as figuras se distinguem dos temas devido ao maior grau de concretude. [...] Figuras são unidades semânticas que acionam a percepção tátil, auditiva, olfativa, visual do sujeito. (DISCINI, 2005, p. 271).

Na perspectiva dessas definições, analisa-se, no poema, a concretização dos temas em figuras que, na instância discursiva e sob o crivo das relações estabelecidas entre os termos do nível fundamental, recebem um determinado investimento tímico de euforia ou disforia.

Em "Meias impressões de Aninha (mãe)", as figuras "Mãe", "Cria teus filhos" e "força maternal" são apreciadas positivamente, recebendo, pois, um investimento eufórico. Desse procedimento discursivo, articulado a uma isotopia (reiteração de unidades semânticas que assegura a coerência sintagmática do discurso), deriva o efeito de ratificação da identidade tradicional da mulher, primordialmente constituída como "boa mãe". Nesta figurativização, que subjaz à produção de sentidos do texto, a representação da mulher como "boa mãe" associa-a com aquela que renuncia aos ilusórios direitos de igualdade e independência, para exercer o dom divino de ser mãe.

Noutra direção, visualizam-se ainda, no poema, elementos do percurso figurativo que, apreciados negativamente, revestem o tema da proscrição da alteridade na construção da identidade feminina. Com a figurativização materializada em "não te deixes castrar"; "Serás um animal somente de prazer" e "Roendo teu osso negro da amargura", emerge o efeito semântico geral do texto, que desqualifica as conquistas femininas, operadas nas esferas da sexualidade e da profissão, sobrepujando-as por uma configuração maternal, "inerente" à identidade da mulher.

\section{Considerações finais}


Embora sejam recobertos por um mesmo nome de autor, os textos de Cora Coralina, analisados neste estudo, apresentam variantes narrativas, temáticas e figurativas que atualizam, de maneiras diferentes, a configuração discursiva do feminino.

A partir da análise desses diferentes percursos narrativos, temáticos e figurativos, depreenderam-se, nesses textos, as seguintes perspectivas distintas de construção de sentidos sobre a identidade da mulher: enquanto no poema Aquela gente antiga, é possível recuperar um percurso de geração do sentido que convalida a alteridade nos processos identitários do feminino, o segundo texto, Meias impressões de Aninha (mãe), é constituído por um percurso que engendra sentidos de desqualificação da alteridade.

Tendo em vista que a depreensão de uma configuração discursiva só é possível a partir do confronto de diferentes discursos, este trabalho reafirma, por fim, a possibilidade de constituição de discursividades distintas no interior de uma obra ou efeito-autor. Nesse movimento, dá visibilidade a diferentes mecanismos, que, sob o crivo da heterogeneidade constitutiva do discurso e de um modelo de arregimentação e leitura dos textos, produz sentidos diversos e, por vezes, opostos.

\section{REFERÊNCIAS}

BARROS, Diana Luz Pessoa de. Teoria Semiótica do Texto. $3^{\text {a }}$ Ed. São Paulo: Ática, 1997. BERTRAND, Denis. Caminhos da Semiótica Literária. Trad. Grupo CASA. Bauru, SP: EDUSP, 2003.

CORALINA, Cora. Vintém de Cobre: meias confissões de Aninha. São Paulo: Global, 2001.

DISCINI, Norma. Comunicação nos Textos. São Paulo: Contexto, 2005.

FIORIN, José Luiz. Elementos de Análise do Discurso. São Paulo: Contexto, 2000.

O Éthos do enunciador. In: CORTINA, Arnaldo \& MARCHEZAN, Renata Coelho.

Razões e sensibilidades: a semiótica em foco. Araraquara: Laboratório Editorial/FCL/UNESP; São Paulo: Cultura Acadêmica Editora, 2004.

FLOCH, Jean-Marie. Alguns Conceitos Fundamentais em Semiótica Geral. Documentos de Estudo do Centro de Pesquisas Sociossemióticas - 1 (2001) - São Paulo: Centro de Pesquisas Sociossemióticas, 2001.

GREIMAS, Algirdas Julien \& COURTÉS, Joseph. Dicionário de Semiótica. São Paulo: Cultrix, 1985.

GREIMAS, A. J. Semântica estrutural. São Paulo: Cultrix \& Edusp, 1976.

1975.

Ensaios de semiótica poética. Trad. Heloysa de Lima Dantas. São Paulo: Cultrix,

Recebido em: 05/10/11

Aprovado em: 26/06/11 